\title{
Application of Nanotechnology in Oil and Gas Industry: Towards Enhanced Oil and Gas Recovery
}

\author{
${ }^{1 *}$ G. Ijeomah, ${ }^{2}$ F. Samsuri, F. ${ }^{3}$ Obite and ${ }^{4}$ M.A. Zawawi \\ ${ }^{1,2}$ Faculty of Electrical \& Electronics Engineering, Universiti Malaysia Pahang, 26600, Pekan, Pahang, \\ Malaysia \\ ${ }^{3}$ Department of Physics, Faculty of Physical Sciences, Ahmadu Bello University, Zaria, Nigeria \\ ${ }^{4}$ School of Electrical \& Electronic Engineering, Universiti Sains Malaysia, 14300 Nibong, Tebal, Penang, \\ Malaysia \\ *guijeomah2@gmail.com
}

\begin{abstract}
The global oil demand and the development of advanced techniques have made the regeneration of previously abandoned oilwells economically attractive. As conventional oil recovery methods near their economic limits, a revolutionary new technology is required to harness maximum oil from these stranded oilwells. Due to its potential to manipulate matter at molecular level, nanotechnology promises to dramatically transform oil and gas industry by enabling enhanced oil and gas recovery. Recently, there has been increasing research interest in the applications of nanotechnology in enhanced oil and gas recovery, where the unique aspects of reservoir management, drilling, production, processing and refinery are redesign. Nanotechnology has the potential to revolutionize the drilling process and accelerate the production of oil and gas by providing a platform that makes their separation in the reservoir more amenable. Nanotechnology can make the industry greener by drastically reducing the oil's carbon footprint in contrast to oils obtained from conventional methods. In this paper, we review the latest trends in the applications of nanotechnology for enhanced oil and gas recovery. We further present scientific advance and new insight into possible future applications. The paper aims to broaden our understanding of the applications landscape of nanotechnology in oil and gas industry.
\end{abstract}

Indexed Terms- Enhanced oil recovery, Reservoir, footprint, greener, sequestering.

\section{INTRODUCTION}

The global demand for energy is projected to increase by $50 \%$ over the next few decades [1] as shown in figure 1, a demanding trend that may be met only by a revolutionary breakthrough in energy science and technology. This is further justified by the current high oil price environment, maturation of oil field at the global arena, increasing oil demand and the discovery of few new oilwells [2]. The promising field of nanotechnology presents attractive alternative through the incorporation of materials with superior characteristics and features suitable for enhanced oil recovery [3]. Nanotechnology has stimulated intense research interest due to its potential for precise oil and gas exploration and recovery.

The outstanding properties of functionalized nanoparticles have generated potential applications in oil reservoirs. For instance, surface-activated nanoparticles can be employed in enhanced oil recovery processes to stabilize emulsions and foams towards mobility control [4-6]. Nanotechnology-based functionalized particles can be injected directly into reservoir formations as sensors to enable enhanced resolution of subsurface imaging resulting in enhanced oil reservoir view, field characterization 
techniques and fluid property monitoring. Nanotechnology-initiated manipulation of interfacial characteristics and molecular modification can lead to enhanced oil and gas recovery.

Nanotechnology-based materials such as nanoparticles [7-8], graphene [9] and carbon nanotubes [10] possess excellent nanoscale properties that can be harnessed for oil and gas exploration and recovery. The miniature size of nanoparticles can result in some beneficial features, such as large surface-tovolume ratio, to which other materials can attach in ways that make for stronger or more lightweight products. The interaction of a solvent with the surface of the particle can overcome the density barrier which usually causes materials to either float or sink in a liquid resulting in the formation of nanofluid.

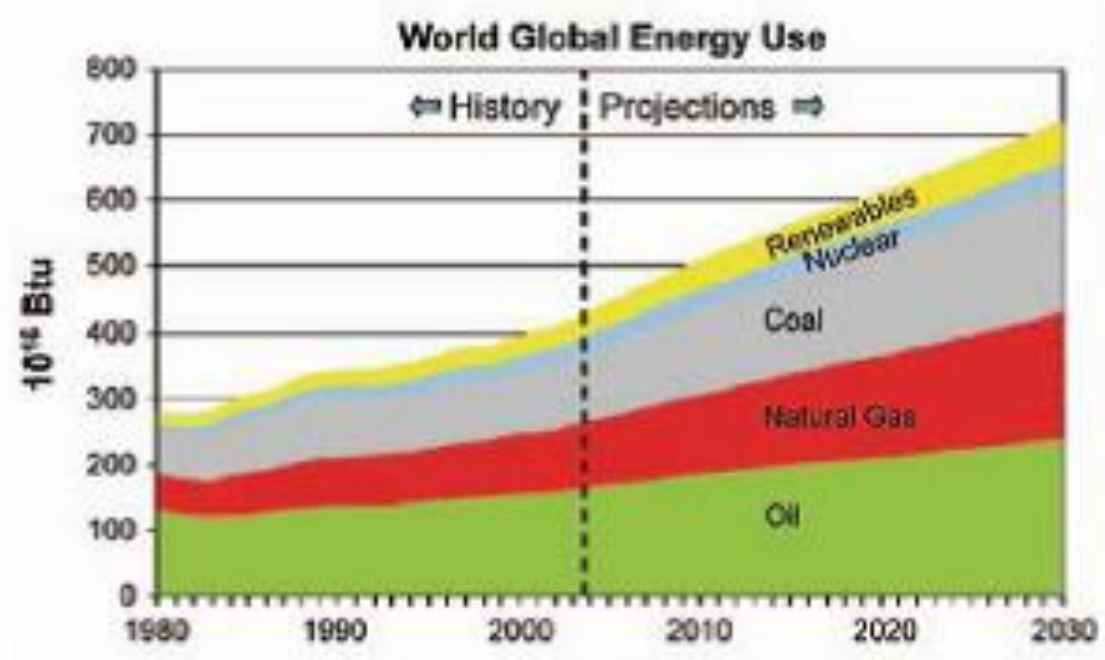

Figure 1: History and projections for global energy use [1]

\section{ENHANCED OIL RECOVERY}

Nanotechnology has been suggested to reduce greenhouse emissions and advance technologies to facilitate carbon capture because of its potential for enhanced oil recovery (EOR). The increase in recovery factor can benefit economy of nations, and this can be achieved through the displacement of large proportions of currently imported oil with expansion of domestic production using nanotechnology-based materials. The oil and gas companies are scouting for oil in a very remote areas; such as deep waters, areas where temperature is below the absolute zero, making field development economically demanding. The increased domestic production can be achieved via enhanced oil recovery, which is a method employed to produce stranded oils following the exhaustion of primary and secondary oil production processes. Conventional methods that utilize carbon dioxide $\left(\mathrm{CO}_{2}\right)$, gas injection, chemical injection, and other methods, can be employed to achieve EOR. However, the scale of oil that can be recovered using these methods is insufficient to meet future projections, making nanotechnology the most promising solution to EOR.

Generally, only a fraction of the total oil in the oil field (original oil in a place or OOIP) can be recovered from the geological reservoir. The fraction of oil that can be produced in a given oil field over time is determined by the geology of the oil field, pumping method and the prevailing economic conditions. The largest proportion of OOIP is extracted during the primary phase of EOR using conventional oil pumping techniques. Over time, production output follows a predictable decline until primary recovery becomes unproductive and uneconomical. This is followed by the secondary recovery phase where the injection of water into the reservoir pushes out additional oils [11-12], with the drilling 
of additional oilwells to access larger proportion of an oil reservoir. About 30\% (roughly one-third) of OOIP can be recovered by the combined primary and secondary recovery processes [13]. The remaining oil, nearly $70 \%$ of the initial resource, is a large and attractive target for EOR methods. The application of the innovative field of nanotechnology in the tertiary recovery phase can lead to the capture of additional (5-20) \% of OOIP [14-15]. The production curve as a function of time is shown in figure 2.

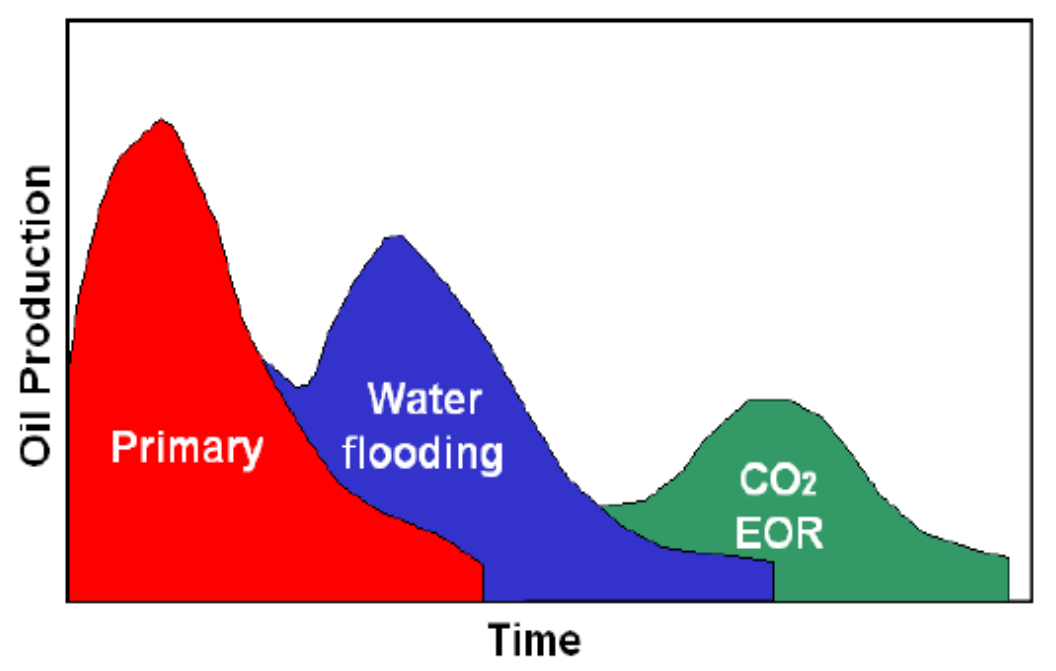

Figure 2: Expected oil production sequence in an oilfield [16]

While $\mathrm{CO}_{2}$ mediated fracturing has remained the cleanest and most effective technique available today to enhance hydrocarbon production [17], its low viscosity limits its beneficial applications in EOR. The authors strongly believe this problem can be bypassed via the use of nanoparticles as alternative to surfactants. To this, the authors note that the higher adhesion energy presented to the fluid interface by the nanoparticles relative to the surfactants, exerts a stabilizing effect on the longer lasting foams. Since the nanoparticles are solids, it is reasonable to argue that surface modified nanoparticle stabilized foams can tolerate severe reservoir and environmental conditions. Such nanoparticles appear to exhibit little retention affinity, making them attractive for EOR flooding processes. A retention of about (10-15) \% was demonstrated by Caldelas et al. [18], although the mechanism playing role in nanoparticle-rock adsorption remained unexplained. In fact, a laboratory study by Shah and Rusheet show the addition of $1 \%$ copper oxide (CUO) nanoparticle increased the viscosity and density of $\mathrm{CO}_{2}$. An increase in viscosity on the order of 140 times is found for a nanoparticle-laced $\mathrm{CO}_{2}$ in comparison to conventional $\mathrm{CO}_{2}$ [19]. In addition, the high viscosity of nanoparticle stabilized emulsions can play role in managing the mobility ratio of a flood process, which can help accelerate oil recovery processes by pushing highly viscous oil from the subsurface, opening up assortment of opportunities for practical applications in reservoir engineering.

Nanomaterials have also shown great potentials in upstream oil industry. Nanomaterials in form of paramagnetic nanoparticles can be employed in formation evaluation and determination of oil saturation in macro volumes of oil reservoirs via the detection of oil-water menisci in reservoir rocks and exploring magnetic resonance imaging (MRI) enhancement procedure [20]. In addition, nanotechnology-based stabilized foams and emulsions can be employed as conformance control agents for EOR, $\mathrm{CO}_{2}$ flooding, interfacial tension and sequestration [21-23]. These stabilized emulsions (or Pickering emulsions) have stimulated a lot of interest in the petroleum sector due to the perceived stability of solid particles to extreme high temperature and saline environments in comparison to surfactants. For instance, 
paramagnetic nanoparticles in viscous emulsion can force the emulsion onto a fracture upon the application of electromagnetic field, thus revealing the stress orientation of fractured reservoir.

The literature is replete with reports of experimental studies elucidating the potentials of nanoparticle surfactants on EOR [24-27]. In one of such studies, Le et al. synergized nanoparticles based on silicon dioxide $\left(\mathrm{SiO}_{2}\right)$ with surfactant for an EOR in high temperature reservoirs. The observed overwhelming potential for EOR application can be attributed to the resistance of nanoparticle-surfactant blend to rock surface adsorption, and thermostability at a temperature of $90^{\circ} \mathrm{C}$ [21]. In a separate study, Suleimanov et al. [22] reported substantial improvement in the throughput of oil displacement flow rate. The oil recovery in an unvaried pore media prior to water breakthrough was found to increase by $51 \%$ for nanoparticle-mediated aqueous surfactant solution, and $17 \%$ without the intervention of nanoparticles.

Onyekonwu and Ogolo have cited Polysilicon nanoparticles (PSPN) as excellent EOR agents . Of special interest is their capability to change rock wettability. Onyekonwu and Ogolo study how the wettability of rocks can be altered by three different PSPNs. Their results indicate more than $50 \%$ improvement for silane-incorporated NWPN, and HLPN, treated with a mono-layer organic compound, after implementing primary and secondary recovery on a water-wet rock [23]. Ju and Fan address the challenges associated with the application of nanopowder in oil fields towards enhanced water injection by exploiting changing wettability effects via adsorption on porous walls of sandstones. They observe a change in the wettability of the surface sandstones from oil-wet to water-wet via the adsorption of untreated polysilicon nanoparticle, LHPN. In addition, the sandstones' effective permeability of water was enhanced, while the absolute permeability was found to be attenuated [24].

Nanoparticles have properties that are particularly promising for certain oil recovery processes due to their solidity and low dimension, being 2-orders of magnitude smaller than colloidal particles. The droplets of nanoparticle stabilized emulsions are so small that they can pass representative pores, and flow seamlessly through reservoir rocks not having much retention [28]. Spherical fumed silica whose wettability is controlled by the extent of decoration with silanol groups on the surface are commonly employed. The material exhibits hydrophilicity when over $90 \%$ of its surface is decorated with silanol groups. This configuration promotes the formation of a stable oil-in-water emulsion. If, however, the silica particles are decorated with only $10 \%$ of silanol groups covering its surface, they become hydrophobic, assuming water-in-oil emulsion status [29]. Nanoemulsions are very stable in the long term, exhibiting strong resistance to the interchange of the dispersed phase between droplets and coalescene [30]. Supercritical $\mathrm{CO}_{2}-\mathrm{in}-\mathrm{H}_{2} \mathrm{O}$ emulsions and $\mathrm{H}_{2} \mathrm{O}$-in -supercritical $\mathrm{CO}_{2}$ emulsion have also been stabilized [31]. The dimensionality of nanoparticles are critical to tailoring their applications. Kanj et al. [32] validate the transport potential of nanoparticles, and determine their functional dimension in reservoir rocks. In another study, Skauge et al. [33] show that silica particles cause no environmental harm as they propagate seamlessly through a pore system, owing to their natural occurrence in the reservoir. The particles also appear not to block pores due to their miniature dimension, making them very attractive for EOR purposes.

Nanotechnology holds enormous potentials in EOR. While the applications of nanotechnology in fields such as medicine, biomedical engineering among others, have gained prominence, its corresponding applications in oil and gas industry has only recently been receiving increasing impetus. Other promising suspects for EOR applications, in addition to silica, are $\mathrm{Al}_{2} \mathrm{O}_{3}, \mathrm{Fe}_{2} \mathrm{O}_{3}$ and $\mathrm{MgO}$. In fact, the combination of these particles in proper proportions has yielded results excellent for EOR applications relative to individual $\mathrm{SiO}_{2}$ [34]. Both micellar flooding and chemical EOR are projected to benefit enormously from nanotechnology in the near future [35].

\section{OIL AND GAS EXPLORATION AND RECOVERY}

The harsh, complicated and challenging nature of today's offshore sites have motivated the struggle for a revolutionary and advanced solutions for oil and gas exploration and recovery. It is strongly believed that any breakthrough in enhanced field and reservoir characterization leads to a corresponding breakthrough in enhanced oil recovery. The traditional field methods utilize magnetic, electrical, electromagnetic and gravitational phenomena to explore petroleum fields [36]. The latent geological 
features of these naturally occurring fields make the search for local perturbations within them one of economic and other interests [37]. Furthermore, these methods can deepen our understanding of the physical and chemical dynamics of the reservoir, leading to the extraction of additional oil and gas. The current conventional technologies, aside from seismic acquisition, can penetrate the wellbore not more than a few inches, and therefore not potential candidates for enhanced oil and gas recovery.

As noted, majority of the conventional technologies lack the needed resolution and the capability to deeply penetrate reservoir lithologies, particularly in tight formations. Under high temperature and pressure bias, most logging tools become unpredictable. This can be attributed to tool failure as a result of attenuation in quality, and possible atrophy of available downhole sensors [38]. By introducing selfsustaining sensors, or at least one that is enabled by injected fluids, it is possible to deep probe the reservoir, with the possibility of understanding the nature and interactions of fluids and rocks and their impact on multi-phase flow. Such sensors can enable the precise comprehension of the physical and chemical properties of rocks and reservoir fluids beyond the wellbore, 3-dimensional distribution of rocks and reservoir fluids, and fluidic dynamic path, thus illuminating hydrocarbon reservoirs [39]. The alteration of electrical, magnetic and optical properties of carbon nanotubes is projected to promote the fabrication of sensors and agents with image-contrasting capabilities. Nanomaterials laced with smart fluids can be used as tracers to sense stress downhole, temperature and pressure in environmentally nonfriendly settings [40].

An enhancement in the drilling processes even by a minuscule factor can improve the efficiency of recoverable oil since non-productive time and operational cost will drastically reduce. This is important given the drastic decline in the average field size in the past few decades or so [41], coupled with nonfrequent discovery of new fields. In addition, environmental regulations and drilling challenges have increased due to E \& P in more harsh and fragile environments. Deepwater drilling, and drilling in arctic regions pose geo-hazards to operators. The oil industry is therefore in dire need of smart materials with mechanically rigidity, physically and chemically stable, morphologically miniature, in nearly all of its E \& P processes [42].

Perhaps, the most promising progress of technology in drilling is synthetic nanoparticles [43-44]. These nanoparticles have emerged as exceptional materials, exhibiting excellent rheological properties. Advanced polymer-based drilling fluids that are physically and chemically bonded to nanoparticles, together with amphiphilic surfactants have been developed. The properties of these fluids can be changed in response to an external stimuli such as salinity and temperature [45]. Nano-crystaline materials combined with advanced drilling fluids can improve the penetration rate while significantly decreasing the wear and tear of drilling equipment [45]. Mud additives based on nanomaterials can improve the thermal conductivity of nanofluids, which presents efficient cooling opportunities for the drill bits and higher operational frequencies [46]. In addition, nano-based additives to increase compressive and flexural strength, and rugged light-weight structural materials have been demonstrated [47].

The need to ensure efficient flow to the surface has made completion one of the most challenging processes of production. Stimulation and completion fluids have been found useful for enhanced flow control, and reservoir productivity [48]. Due to their excellent rheological properties, capacity to maintain low formation damage relative to cross linked polymer fluids, viscoelastic fluids can be employed in oil industry for fracturing, gravel-packing and fracture-packing. The viscosity of such fluids can be maintained at acceptable threshold at high temperature, and the loss of viscoelastic surfactant fluids can be adequately controlled without formation damage using nanomaterials [49].

The challenge of upgrading heavy organic compounds still remains. The production of heavy organic compounds including bitumen can be influenced by deposition and flocculation of asphaltenes. However, nickel-based nano- and micro particles dispersed in heavy oil matrices have enabled substantial removal of asphaltenes in in situ solution [50]. In addition, novel nano-membranes that can separate metal impurities in heavy oil, and gas impurities in tight gas have been developed. These membranes are capable to enhance the exploration of tight gas through the provision of efficient methods for removal of impurities [45]. 
Nanotechnology has the potential to raise the prospect of stranded gas resources and unconventional EOR. However, there are challenges to be addressed; infrastructural efficiency of liquefied natural gas (LNG), advancing gas-liquid (GTL) technology, quality assurance in LNG, construction of floating GTL platforms, storage issues, development of super-pipelines, transport of compressed natural gas $(\mathrm{CNG})$, regasification, production of gas and methane hydrate and conveying them by wire rather through pipelines. These challenges can be addressed through the development of nanoscale membranes and nanocatalyst for production of GTL, and the creation of nanostructures to address CNG transport. Nanomembranes can be employed to enable GTL production, remove impurities, and thus guarantee enhanced exploitation of tight gas.

\section{NANOPARTICLE TRANSPORT}

Formation damage is perhaps one of the biggest hurdles in the petroleum industry today, and can occur at any stage of oil recovery from subsurface reservoirs, including drilling, hydraulic fracturing, and production operations. This is due to inauspicious processes in EOR methods. Probable indicators include formation deformation under stress and fluid shear, permeability impairment and skin damage [51]. Nanoparticle transport has become an issue nowadays as a result of retention of nanometer-sized particles in porous media, with potential to damage formation properties of reservoirs.

A porous media is a complex structure with throats and pore bodies housing a range of dimensions. Of concern to many industries, including oil and gas, is particle retention in porous media, which limits particle transport only to the extent to which particles are retained by the porous medium. Oil and gasbearing reservoir rocks can be influenced by particle invasion [52].

The study of motion of particles in a porous media is complicated due to the nature and complexity of forces controlling the movement of particles in the porous media. However, the literature detail some solutions to these problems. One of such mechanisms exploits the electrostatic interaction between the solid exterior of the pores and the migrating particles, and the particle adsorption on the rock exterior due to Brownian motion [52]. Mechanical entrapment has been identified as another solution, yielding good retention [53]. Here, larger particles normally block the narrow pore throats. In addition, it is believed that mechanical entrapment is mirrored in the inability of the particle concentration in the effluent to reach the injected concentration, or it would do so following the injection of significant volume of particles [33].

In the entrapment mechanism, pores larger than the particle size are usually blocked. The density difference between the carrying fluid and moving particles, causes gravity settling or sedimentation. As a result, pore throat narrows, increasing flow velocity. This forces water molecules to accelerate faster than denser particles, which causes accumulation to occur. The gravity settling causes the pore throat to constrict, and is eventually blocked. The flow rate, particle concentration, pore size distribution and effective hydrodynamic size are among the factors that characterize the entrapment process [54]

These mechanisms are particularly important when injecting nanomaterials or other agents in a porous media. The blocking of pores can attenuate permeability, damage the reservoir and trigger unpredictable flow pattern. The use of blocking agents on the reservoir to avert fluid channeling via high permeable zones is attractive in this aspect [55]. However, most EOR methods require that the employed agents and the blocking pores (fractures) have different targets. Blocking pores and reducing permeability are therefore undesirable, with several factors affecting the extent of blocking. Among the factors that impact on the permeability decline are, flow rate, ironic strength, fluid viscosity, $\mathrm{pH}$ and particle concentration. Experimental result show that large particle sample and small fluid velocity result in shallow and severe damage, with higher concentration leading to severe permeability damage [52]

Adsorption in nanoparticle transport in porous media can occur through physicochemical interactions, which include hydrodynamic force, collision of particle-media, thermodynamic force and particle surface static interaction. The collision of particle-media is triggered via the blockade of the nanoparticle path with sand grains. This causes the nanoparticle to be retained at the still point on the 
grain surface. Following Derjaguin-Landau-Verwey-Overbeek theory, the nanoparticle-surface static interactions incorporate double-layer repulsion and van der Waals forces of attraction. Applying Guzman formalism [56], the potential between the grain surface and the nanoparticle, often called van der Waals potential, can be written as,

$\Phi_{v}=-\frac{A_{H}}{6}\left[\frac{a}{h}+\frac{a}{h+2 a}+\ln \left(\frac{h}{h+2 a}\right)\right]$

where a represents the radius of the nanoparticle, $\mathrm{h}$ is the smallest separation distance between the nanoparticle surface and the collector surface, and $A_{H}$ is the Hamaker's constant. Equation (1) enables us to estimate the van der Waal's nanoparticle-sand grain interaction energy in relation to the particle dimension and distance between the two objects. Larger particles were found to give stronger attraction. With fixed sized particles, however, the van der Waal's force was observed to decay quickly as the separation between the nanoparticle and substrate is increased.

A wealth of mathematical and experimental models connecting the changes in reservoir properties to nanoparticle adsorption have been presented. Zhou et al. \& Ju et al. [57-58] study the permeability and wettability changes due to adsorption of nanoparticles on rock surfaces. They assess porosity changes and absolute permeability triggered by particle injection, giving instantaneous porosity as,

$\phi=\phi_{o}-\sum \mathrm{V} \phi$

where $\sum \mathrm{V} \phi$ is the change in porosity as a result of particle retention. In addition, the permeability expression for Xianghui and Civan model is redesigned to incorporate instantaneous permeability as follows,

$$
K=K_{o}\left[(1-f) k_{f}+\frac{f \phi}{\phi_{o}}\right]^{n}
$$

where $K$ is the existing local permeability, $K_{o}$ is the initial permeability, $\phi$ is the existing local porosity, $\phi_{o}$ is the initial porosity, $f$ is the flow efficiency factor with cross-section area open to flow, $k_{f}$ is fluid seepage constant permitted via plugged cores [58].

Ju et al. [58] investigate alternation of relative permeability due to injection of nanoparticles. Nanoparticles that spread on rock surfaces have potential to alter the wettability of the rocks. The mechanism of wettability is paramount to determining the relative permeability of a porous media. The overall exterior per unit bulk volume of the porous medium is found to be spanned by nanoparticles that were entrapped at pore throats or adsorbed on pore surfaces when the complete exterior area contacted by the fluids per bulk volume of the porous media is greater than or at least equal to the specific area of the sand core. This provides a means to characterize wettability via the properties of nanoparticles. Additional deposition of nanoparticles has the effect of triggering further attenuation in permeability and porosity [58]. The relative permeability to oil and water prior to injection of nanoparticles are given as $K_{r o}$ and $K_{r w}$. For a surface per unit bulk volume of a porous media not completely occupied by nanoparticles, the relative permeability of oil and water become reduced to a linear function of the surfaces occupied by the nanoparticles [58].

Further experiment by $\mathrm{Ju}$ and Fan [59] on porosity and permeability changes as a result of nanoparticle flooding, show the ratios $K / K_{o}$ and $\phi / \phi_{o}$ to attenuate as the volume of injected nanofluid is increased. In addition, numerical analysis show that permeability and porosity ratio close to the inlet is smaller relative to the one at the outlet. Both ratios are found to increase gradually towards the initial value as distance approaches unity since both are functions of dimensionless distance. This implies that the adsorption of nanoparticles at pore throat blocking, and pore walls, occur at higher frequency closer to the inlet. 
As established, wettability can be altered by different nanoparticles depending on their surface coating. To date, only polysilicon nanoparticles have been examined, with particular focus on hydrophobicity [60]. The wettability of a rock surface can react differently to different types of polysilicon. The polysilicon nanoparticles LHPN, in its pristine form, can transform wet-water to strongly water-wet or cause an oil-wet rock water-wet. When treated with a monolayer organic compound, HLPN can change a water-wet rock oil-wet, or cause already oil-wet rock strongly oil-wet. A saline-treated NWNP can achieve intermediate wetness by imparting simultaneous strongly oil-wet and strongly water-wet properties to rocks or strips the rock of its oil-or water-wet status [23]. The polysilicon nanoparticles spread over and stick to the rock surface in order to enable its wettability. The concentration and dimension of the nanoparticles are important factors for optimal distribution. Also playing role in determining wettability and change of contact angle, is degree of dispersion and several studies have addressed this [61-62].

Vafaei et al. [63] investigate the effect of nanoparticles on the contact angle of sessile droplets. The study links nanoparticle dimension and concentration in solution to variation in the contact angle of the droplets. For a particular (same) droplet volume, the contact angle increases linearly with concentration reaching a peak, before decreasing with increasing concentration. We can further deduce from these results that the smaller nanoparticles were more efficient in raising the contact angle. Two mechanisms play role in improving the contact line motion impacted by the presence of nanoparticles as proposed by Sefianne et al. [64]. Both mechanisms lead to enhancement, which can result from either structural disjoining pressure or adsorption of nanoparticle on the surface. Wasan et al. [65] investigate the role of disjoining pressure in wettability and nanofluids spreading on a solid surface. Disjoining pressure is triggered by two reciprocally overlapping surface layers, and it results from the effects of opposing forces in nature. The electrostatic forces, the forces of molecular interaction, the forces of elastic resistance of solvated, or adsorbed solvated films can function as components of a disjoining pressure. The structural disjoining pressure acting towards a wedge from the bulk solution is the driving force for the spread of a nanofluid, consistent with Wasan et al. [65] observation. The vertex is dominated by the film tension because the particles are restructuring in the wedge confinement. The nanofluid spread at the tip of the wedge as the top of the wedge experiences higher film tension. This enhances the dynamic spreading behaviour of the nanofluid [65]. Figure 3 shows the formation of nanoparticle structure within the wedge film for an oil droplet-solid interface. The nanoparticles were found to exert a large pressure on the wedge film relative to the bulk solution. This surplus pressure, also known as disjoining pressure, functions to separate the two phases from each other [65].

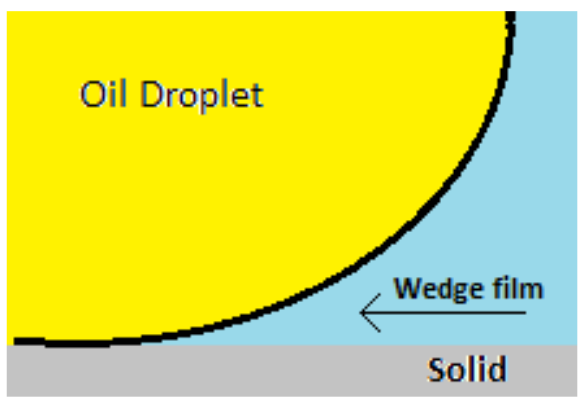

b

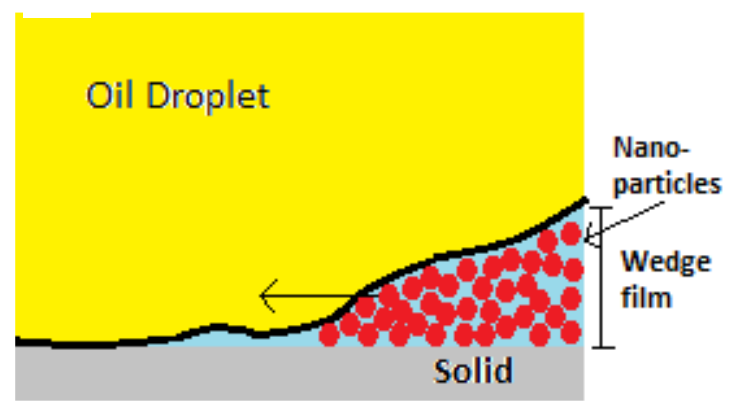

Figure 3 (a) Oil droplet on a solid surface, (b) Nanoparticle structuring in the wedge-film, resulting in structural disjoining pressure at the wedge vertex [65]. 


\section{NANOTECHNOLOGY IN THE OIL ENVIRONMENT}

While the creation and employment of engineered nanostructured particles form a vital part of the nanoelectronic revolution, the guarded and responsible application of materials present numerous challenges [66]. Research and assessment is necessary to instil a shared comprehension and sufficient awareness of nanotechnology development and possible risk management issues that must be addressed [67]. The oil and gas industry needs to leverage on the findings and best practices from research institutes and other industries that utilize nanotechnology. This will help foster their understanding of occupational safety, environmental and health implications of nanotechnology [68].

To this end, nanotechnology represents a novel generation of environmental remediation technologies that could be particularly promising to shoot down most challenging environmental problems. In fact, nanotechnology has the potential to make the industry considerably greener. Nanoscale iron particles can be effective enough for transportation and detoxification of various environmental contaminants such as chlorinated organic solvents and PCBs [69].

Nanotechnology based particles and filters can play role in cleaning the soil and water of heavy metals such as mercury, and remove volatile organic compounds from oil vapour. Precise nanoscale membranes can be exploited to control fluid wettability. Nanofluids that operate on the nanoscale can be employed in the oil industry for many applications. The addition of nano-fabricated particles to a fluid can ultimately enhance some of its properties, presenting numerous remediation applications. The nanoparticles can be suspended in the liquid phase in low volumetric proportion. The liquid phase can be any liquid such as conventional fluid mixtures, or water. The fluids are designed essentially from inorganic nanoparticles which are insoluble and immiscible with the target liquid environment. They are designed to be compatible with the reservoir fluids and are environmentally friendly. Nanofluids can be attractive for alternation of wettability, anticorrosive coatings, drag reduction and binders for sand consolidation. Nanoparticles laced with steel casing and cement may offer advanced protection of groundwater zones from saline water, natural gas and deep oil zones [70]. The use of iron nanoparticles with zero valency for remediation of contaminated soil and ground water provides yet another opportunity for environmental remediation [71-72]. Nanomembranes in the form of reverse osmosis membrane (ROM) have been developed for waste water remediation and seawater desalinization [7377]. Photo-activated nanoparticles have also been investigated for their possible capacity to remove contaminants from various media particularly oil and gas.

Oil spillage has remained a topical issue in petroleum exploration. According to the U.S. Environmental Protection Agency (EPA), about 14,000 oil spills are reported each year [78]. Conventional cleaning methods utilize biological agents, dispersing agents and gelling agents. However none of these methods can recover the lost oil. Recent developments in nano-wires based on potassium manganese oxide can clean up oil and other organic pollutants while making oil recovery possible. The mesh formed by these nanowires can absorb in the orders of 20 times its weight hydrophobic liquids while shunning water with its water repelling coatings. As the potassium manganese oxide is essentially stable at elevated temperatures, the oil can be boiled off the nanowires, presenting opportunity for their reuse.

The handling of environmental hazards can be enhanced to make it unchallenging to win public and politic acceptance for oil and gas E\&P, particularly in fragile areas. Although nanotechnology can help to address these problems, the need to comprehend and accept the health and safety issues remains paramount. Any technique to make the handling of environmental contaminants economically profitable, easier and more effective is priceless in so far as it is practically risk-free.

\section{PRACTICAL CONCERNS}

An important area of concern is the effect that industrial-scale manufacturing and use of nanomaterials would have on human health and the environment, as nanotoxicology research show. Although progress appear to have been made toward understanding the health and environmental consequences of these 
materials, challenges remain for future research. However, whether a substance is materially dangerous depends on determining not only its potential hazards, such as toxicity, but also the threshold to which a living cell could be exposed. The responsible employment of manufactured nanomaterials in environmental applications, and commercial products, in addition to prudent management of the associated risks, demands a refined understanding of their impacts, mobility and bioavailability on a wide range of organisms.

There is dearth of ecotoxicological profile for any of the nanomaterials available today and the existing scientific results showcase potentially serious health and environmental fear factors. Much more research and ecotoxicological modelling and simulation is therefore paramount for macro-scale release of nanomaterials into the environment for the purpose of remediation or other uses. Nanotechnology has the potential to deliver useful water treatment in some areas [79]. However, even if ignoring potential human toxicity issues, concern is high that other water treatment techniques, including effective, community-controlled methods will be benched as priority is given to copyrighted, corporate controlled nano-water treatment applications. In addition, Şengül et al. [80] have demonstrated that the production of nanomaterials has an unexpectedly large ecological footprint. This was attributed to high waste generation, high energy and water demands of processing, small product yields, highly specialised production terrain, the manufacture and employment of greenhouse gases such as methane and the use of toxic chemicals and solvents such as benzene.

Khanna et al. [81] show, in a separate life cycle study of carbon nanofibre production, that nanoparticles possess incredible potential to contribute to environmental or human toxicity, global warming and depletion of ozone layer by as much as orders of 100 greater per unit of weight relative to conventional materials.

Nanomaterials, in themselves, constitute a new generation of toxic chemicals. The creation of free radicals in many nanomaterials increases as particle size scales down, as does toxicity. Studies have shown that commercial applications of nanomaterials can negatively impact cellular function, damage human DNA and can even trigger cell death. A small but growing body of scientific evidence pointing to toxicity of nanomaterials to commonly used environmental indicators such as algae, invertebrate and fish species has been established [82-86]. Some strains of nanomaterials have also been shown to impair reproductive functions in earthworms [87], with the possibility of a similar effect in animals and humans contemplated. A new evidence points to the capability of nanomaterials to criss-cross generations in both animals [88-89] and plants [90].

Other studies show that carbon nanotubes have toxic properties when absorbed through the skin [91]. More controversial is whether inhalation or ingestion of carbon nanotube or of impurities associated with their production, trigger lung damage in experimental animals [92-95]. Additional research work is needed in this area to provide scientific basis for policy framework to deal with the uncertainties and risks.

\section{FUTURE PERSPECTIVES}

Nanotechnology is projected to have overwhelming applications in the future of oil and gas industry. Molecular Nanotechnology (MNT) is projected to lead to the design of ubiquitous smart materials. Such smart materials are inherently rugged with lightweight features that can help reduce weight requirements on onshore platforms. These materials represent a low cost, environmentally friendly solutions to controlled oil and gas separation. Their smart surfaces possess the capacity to alternately attract and repel oil in an aqueous solution, making them highly beneficial to a wide pool of industries, including petroleum, petrochemical, chemical and even pharmaceutical industries. In addition, their regenerative ability makes them very attractive for oil spill cleanup.

One famous category of smart materials widely employed in oil and gas industries is smart cements. Well cementing is perhaps one of the most crucial and predominant operations implemented in an oil and gas well. Cement is usually employed to isolate or seal off oil, gas and $\mathrm{H}_{2} \mathrm{O}$ from the wellbore. Conventional cement-based materials, to include concrete, cement paste and cement mortar 
traditionally brittle, exhibiting poor tensile strength relative to materials such as polymers and metals [96]. On the contrary, incorporation of nanoparticles into cements can make them smarter, opening the door for a wealth of oil and gas applications. Cements based on nanocomposites have been reported to not only mechanically reinforce concrete, but also render them peizoresistive (self-sensing), and thus confers stress, crack and strain monitoring capability on the cement structure [96]. In addition, the potential is enormous for oil and gas wells, possibly assisting to resolve age-long challenge of confirming that cement is mixed, distributed and hardened with precision inside wells, where oil- and gas-bearing zones are isolated.

Nanosensors are predicted to have overwhelming applications in the oil sector. Existing sensors based on carbon nanotubes have shown excellent sensitivity and sharp response towards gaseous molecules than conventional sensors [97]. As oil and gas production shifts to non-conventional environment, rugged sensors that can handle the hotter, harsher operating environment will be in high demand. The development of rugged sensing platform based on an array of nanomaterials that is focused not only on collection of reliable data on oil and gas fields, but also on expanding the magnitude of the information that can be captured and analysed, are projected. This can potentially enhance field and well operations that are safer and more efficient, as well as enable efficient and environmental footprint of oil and gas producing technologies.

Other possible future possibilities of nanotechnology in petroleum industry include:

- Nanotechnology-based sensors for enhanced temperature and pressure ratings in deep-located wellbores and hostile environment.

- Novel imaging and computational techniques for enhanced discovery, sizing and reservoir characterization

- Miniature drill-hole assessment instruments to drastically beat down drilling cost and to provide improved environmental sensitivity due to less drill waste

- Improved elastomers

- Nanobots that track the flow of hydrocarbons, monitor individual channels and pores, map zones that require intensified water injection or oil extraction or other EOR stimulating agents.

\section{CONCLUSION}

This paper has provided state-of-the-art review of latest research progress and trends in the applications of nanotechnology in oil and gas industry. Sufficient insight into possible future applications have been presented to give direction for future work.

\section{REFERENCES}

[1] "Energy Information Administration, System for Analysis of global Energy Markets". Appendix 1 of International Energy outlook, 2006.

[2] Aladasani A., Bai B. "Recent Developments and Updated Screening Criteria of Enhanced Oil Recovery Techniques", SPE 130726 presented at the CPS/SPE International Oil and Gas Conference and Exhibition. Beijing, China, 8-10 June: Society of Petroleum Engineers, 1-24, 2010.

[3] Negin C., Ali S., Xie Q. "Application of nanotechnology for enhancing oil recovery- A review", Petroleum 2, 324-333, 2016.

[4] Manan M. A., Farad S., Piroozian A., Esmail J. A. "Effects of Nanoparticle Types on Carbon Dioxide Foam Flooding in Enhanced Oil Recovery”, Petroleum Science and Technology, 33, 1286-1294, 2015.

[5] Zhang T., Davidson A., Bryant S.L., Huh C. "Nanoparticle-Stabilized Emulsions for Applications in Enhanced Oil Recovery", SPE paper 129885, presented at SPE Improved Oil Recovery Symposium, Tulsa, OK, 2010. 
[6] Espinosa D., Caldelas F., Johnston K.P., Bryant S.L., Huh C. "Nanoparticle-Stabilized Supercritical CO2 foams for Potential Mobility Control Applications", SPE paper 129925, presented at SPE Improved Oil Recovery Symposium, Tulsa, OK, 2010.

[7] Kamal M. S., Adewunmi A. A., Sultan A. S., Al-Hamad M. F., Mehmood U. "Recent Advances in Nanoparticles Enhanced Oil Recovery: Rheology, Interfacial Tension, Oil Recovery, and Wettability Alteration'”, Journal of Nanomaterials 2017, 2473175, 1-15, 2017.

[8] Sun X., Zhang Y., Chen G., Gai Z. "'Application of Nanoparticles in Enhanced Oil Recovery: A Critical Review of Recent Progress", Energies 10, 345, 1-33, 2017.

[9] Luo D., Wang F., Zhu J., Cao F., Liu Y., Li X., Wilson R. C., Yang Z., Chu C.-W., Ren Z. "Nanofluid of graphene-based amphiphilic Janus nanosheets for tertiary or enhanced oil recovery: High performance at low concentration", Proc Natl Acad Sci. 113, 7711-7716, 2016.

[10] Alnarabiji M. S., Yahya N., Shafie A., Solemani H., Chandran K., Abd Hamid S. B., Azizi K. "The Influence of Hydrophobic Multiwall Carbon Nanotubes Concentration on Enhanced Oil Recovery", Procedia Engineering 148, 1137-1140, 2016.

[11] Alagorni A. H., Yaacob Z. B., Nour A. H. “'An Overview of Oil Production Stages: Enhanced Oil Recovery Techniques and Nitrogen Injection", International Journal of Environmental Science and Development 6, 693-701, 2015.

[12] Ivan Dario Pinerez Torrijos "Enhanced oil recovery from Sandstones and Carbonates with 'Smart Water', Doctoral thesis. University of Stavanger, Norway, 2017.

[13] Hirasaki G.J., Miller C.A., Puerto M. 'Recent Advances in Surfactant EOR”, SPE Journal, 16, 889-907, 2011.

[14] “Enhanced Oil recovery / $\mathrm{CO}_{2}$ Injection", USDOE/National Energy Technology Laboratory (NETL), http://www.fossil.energy.gov/programs/oilgas/eor/index.html.

[15] "Carbon Dioxide Enhanced Oil Recovery", USDOE/NETL, March. http://www.netl.doe.gov/technologies/oil-gas/Publications/EP/small $\mathrm{CO}_{2}$ EOR Primer, 2010.

[16] Tzimas E., Georgakaki A., Garcia Cortes C., Peteves S.D. "Enhanced Oil Recovery using Carbon Dioxide in the European Energy System", DG JRC, Institute for Energy Petten, The Netherlands. Report EUR 21895 EN, December 2005.

[17] http://www.lindeus.com/en/industries/power_and_energy/upstream_oil_gas/fraccing/index. html

[18] Caldelas F.M. "Experimental Parameter Analysis of Nanoparticle Retention in Porous Media". Thesis, The University of Texas - Austin, 2010.

[19] Shah R. D. "Application of Nanoparticle Saturated Injectant Gases for EOR of Heavy Oil", SPE Annual Technical Conference and Exhibition, New Orleans, Louisiana, USA, 2009.

[20] Tretheway D. C. Meinhart, C. D. "Apparent Fluid Slip at Hydrophobic Microchannel Walls", Phys. Fluids 14, L9-L12, 2002.

[21] Le N, Pham D. K., Le K. H., Nguyen P. T. "'Design and Screening of Synergistic Blends of $\mathrm{SiO} 2$ Nanoparticles and Surfactants for Enhanced Oil Recovery in High-Temperature Reservoirs", Advances in Natural Sciences: Nanoscience and Nanotechnology 2, Published 21 July, 2011.

[22] Suleimanov B., Ismalov F., Veliyev E. "Nanouid for Enhanced Oil Recovery", Journal of Petroleum Science and Engineering, 6 June, 2011.

[23] Onyekonwu M. O., Ogolo N. A. "Investigating the Use of Nano-particles in Enhancing Oil Recovery", Nigeria Annual International Conference and Exhibition, Tinapa - Calabar, Nigeria, 31 July - 7 August, 2010.

[24] Fukumoto T. "The development of water-based consolidants for Sydney sandstone in heritage buildings', Doctoral thesis, University of Technology, Sydney, 2017.

[25] Pandey R. K., Krishna S., Rana J., Hazarika N. K. "Emerging applications of nanotechnology in oil and gas industry", International Journal For Technological Research in Engineering 3 2347-4718, 2016. 
[26] Mortazavi E., Masihi M., Ghazanfari M. H. "An Influence of Polymer-Alkaline and Nanoparticles as Chemical Additives on the Immiscible Displacement and Phase Relative Permeability", Iranian Journal of Oil \& Gas Science and Technology 5, 14-31, 2016.

[27] Tajimiri M., Ehsani R. “The Potential of Zno Nanoparticles to Reduce Water consuming in Iranian Heavy Oil Reservoir’. J. Water Environ. Nanotechnol. 1, 84-90, 2016.

[28] Damgaard T. S. "Experimental Investigation of Nanoparticle Adsorption and Pore Blockage in Intermediate Wet Berea Sandstone', Master thesis, Norwegian University of Science and Petroleum, Norway, 2017.

[29] Zhang T., Davidson A., Brytant S. L., Huh C. "Nanoparticle-Stabilized Emulsions for Application in Enhanced Oil Recovery". SPE Improved Oil Recovery Symposium, Tulsa, Oklahoma, USA, 24-28 April, 2010.

[30] Kong X., Ohadi M. M. "Application of Micro and Nano Technologies in the Oil and Gas Industry- An Overview of the Recent Progress", Abu Dhabi International Petroleum Exhibition \& Conference,1-4 November, 2010.

[31] Dickson J., Johnston K., Binks B. "Stabilization of Carbon Dioxide-in Water Emulsions with Silica Nanoparticles", Langmuir The Acs Journal Of Surfaces And Colloids, August 14, 2004.

[32] Kanj M. Y., AlYousif Z., Funk J. "Nanofluid Corewood Experiment in the ARAB-D", SPE Saudi Arabia Section Technical Symposium and Exhibition, Aikhobar, Saudi Arabia, 9-11 May, 2009.

[33] Skauge T., Spildo K., Skauge A. "Nano-sized Particles For EOR", SPE Improved Oil Recovery Symposium, Tulsa, Oklahoma, USA, 24-28 April, 2010.

[34] Ogolo N., Olafuyi O., Onyekonwu M. "Enhanced Oil Recovery Using Nanoparticles", SPE Saudi Arabia Section Technical Symposium and Exhibition, Al-Khobar, Saudi Arabia, 8-11 April, 2012.

[35] Mokhatab S., Fresky M. A., Islam M. R. "Application of Nanotechnology in Oil and Gas E\&P," JPT, Society of Petroleum Engineers, April, 2006.

[36] Streich, R. "Controlled-Source Electromagnetic Approaches for Hydrocarbon Exploration and Monitoring on Land. Sur Geophys, 37, 47-80, 2016.

[37] Kearey P., Brooks M., Hill I. "An Introduction to Geophysical Exploration", Blackwell Science Ltd. 14, 2002.

[38] Al-Mahrooqu S. Walton W. "Well Logging and Formation Evaluation Challenges in the Deepest Well in the Sultanate of Oman (HPHT Tight Sand Reservoirs)", SPE Middle East Unconventional Gas Conference and Exhibition, 31 January-2 February, 2011.

[39] Advanced Energy Consortium "Request for Proposal Micro- and Nanosensors for Oil and Gas Exploration and Production Applications". Issued 14 July, 2008.

[40] Vryzas Z., Kelessidis V. C. "Nano-Based Drilling Fluids: A Review”, Energies 10, 540, 234, 2017.

[41] Shihab-Eldin A. "New Energy Technologies: Trends in the Development of Clean and Efficient Energy Technologies", Organization of the Petroleum Exporting Countries -OPEC Review, December, 2002.

[42] Amanullah M., Al-Tahini A. M. "Nano Technology - Its Significance in Smart Fluid Development for Oil and Gas Field Application", SPE Saudi Arabia Section Technical Symposium, AlKhobar, Saudi Arabia, 9-11 May, 2009.

[43] Al-Yasiri M. S., Al-Sallami W. T. "How the drilling Fluids Can be Made More Efficient by Using Nanomaterials", American Journal of Nano Research and Applications 3, 41-45, 2015.

[44] Nasser J., Jesil A., Mohiuddin T., Al Ruqeshi M., Devi G., Mohataram S. "Experimental Investigation of Drilling Fluid Performance as Nanoparticles", World Journal of Nano Science and Engineering 3, 57-61, 2013.

[45] Krishnamoortu R. "Extracting the Benefits of Nanotechnology For the Oil Industry", JPT, Society of Petroleum Engineers, November, 2006. 
[46] Amanullah M., Al-Arfaj M., Al-Abdullatif Z. "Preliminary Test Results of Nano-based Drilling Fluid for Oil and Gas Field Application", SPE/IADC Drilling Conference and Exhibition, Amsterdam, The Netherlands, 1-3 March, 2011.

[47] Engeset B. "The Use of Nanotechnology in the Petroleum Industry", Project Thesis, December, 2011.

[48] Pourafshary P., Azimipour S., Motamedi P., Samet M., Taheri S., Bargozin H., Hendi S. "Prior Assessment of Investment in Development of Nanotechnology in Upstream Petroleum Industry", SPE Saudi Arabia Section Technical Symposium, AlKhobar, Saudi Arabia, 9-11 May, 2009.

[49] Huang T., Crews J. B. "Nanotechnology Applications in Viscoelastic Surfactant Stimulation Fluids", European Formation Damage Conference, Scheveningen, The Netherlands, 30 May-1 June, 2007.

[50] Nassar N., Al-Jabari M., Husein M. "Removal of Asphaltenes from Heavy Oil by Nickel Nano and Micro Particle Adsorbents", Proceeding (615) Nanotechnology and Applications, January $1,2008$.

[51] Civian F. "Reservoir Formation Damage: Fundaments, Modeling, Assessment, and Mitigation", Elsevier Inc., 2007.

[52] Gao C. "Factors Affecting Particle Retention In Porous Media', Emirates Journal for Engineering Research, 12, September, 2007.

[53] Predelus D., Lassabatere L., Loius C., Gehan H., Brichart T., Winiarski T., Angulo-Jaramillo, R. "Nanoparticle transport in water-unsaturated porous media: effects of solution ionic strength and flow rate, J Nanopart Res 19, 1-17, 2017.

[54] Bolantaba S., Skauge A., Mackay E. "Pore Scale Modelling of Linked Polymer Solution (LPS) - A New EOR Process", European Symposium on Improved Recovery, Paris, France, 27-29 April, 2009.

[55] Seright R., Liang A "Comparison of Different Types of Blocking Agents", European Formation Damage Conference, The Hauge, Netherlands, 15-19 May, 2009.

[56] Guzman K.A.D., Finnegan M.P., Banfield J.F. "Influence of Surface Potential on Aggregation and Transport of Titania Nanoparticles”, Environmental Science \& Technology, 40, 7688-7693, 2006.

[57] Zhou L., Das S., Ellis B. R. "Effect of Surfactant Adsorption on the Wettability Alteration of Gas-Bearing Shales", Environmental Engineering Science 33, 766-776, 2016.

[58] Ju B., Shugao D., Zhian L., Tiangoa Z., Xiatao S., Xiaofeng Q. "A Study of Wettability and Permeability Change Caused by Adsorption of Nanometer Structured Polysilicon on the Surface of Porous Media", SPE Asia Paci_c Oil and Gas Conference and Exhibition, Melbourne, Australia, 8-10 October, 2002.

[59] Ju B., Fan T. "Experimental Study and Mathematical Model of Nanoparticle Transport in Porous Media", Powder Technology, Accepted 22 December, 2008.

[60] Sabet M., Hosseini S. N., Zamani A., Hosseini Z., Soleimani H. "Application of nanotechnology for enhanced oil recovery: A review", Trans Tech Publications 367, 149-156. Doi: 10.4028/www.scientific.net/DDF.367.149, 2016.

[61] Schuster J. M., Schvezov C. E., Rosenberger M. R. "Influence of Experimental Variables on the Measure of Contact Angle in Metals Using the Sessile Drop Method", Procedia Materials Science 8, 742-751, 2015.

[62] Xia H., Zhao L., Sun Y., Yuan S. "'The Influence of Pore Structure Parameters on the Digital Core Recovery Degree'”, AIP Conference Proceedings 1839, 020034, 2017.

[63] Vafaei S., Tasciuc T. B., Podowski M. Z., Purkayastha A. "Effect of nanoparticles on sessile droplet contact angle', Institute of Physic Publishing, Nanotechnology 17, 14 April, 2006.

[64] Sefiane K., Skilling J., MacGillicray J. "Contact line motion and dynamic wetting of nanofluid solutions", Advances in Colloid and Interface Science, Volume 138, Issue 2, May, 2008. 
[65] “The Great Soviet Encyclopedia', 3 ${ }^{\text {rd }}$ Edition, 1970-1979, Entered 28.04., 2012.

[66] Maynard A., Kuempel E. "Airborne Nanostructured Particles and Occupational Health", Journal of Nanoparticle Science, Volume 7, Number 6, December, 2005.

[67] Sun Y. D., Zheng-Ming., Chen, H. W. "Nanotechnology Challenges: Safety of Nanomaterials and Nanomedicines", Asian Journal of Pharmaco-dynamics and Pharmacokinetics, December, 2006.

[68] Ostraat M. L. " Occupational and Environmental Implications of Nanotechnology in E\&P: An Overview", SPE Americas E\&P Health, Safety, Security, and Environmental Conference, Houston, Texas, USA, 21-23 March, 2011.

[69] Zhang W. "Nanoscale Iron Particles for Environmental Remediation: An Overview", Journal of Nanoparticle Research, 5, 3-4, 2003.

[70] http://www.csur.com/sites/default/files/Undersatnding_FINAL.pdf

[71] Shi Z., Fan D., Johnson R. L., Tratnyek P. G., Nurmi J. T., Wu Y., Williams K. H. " Methods for characterizing the fate and effects of nano zerovalent iron during groundwater remediation", Journal of Contaminant Hydrology 181, 17-35, 2015.

[72] O'Carrol D., Sleep B., Krol M., Boparai H., Kocur C. "Nanoscale zero vacant iron and bimetallic particles for contaminated site remediation", Advances in Water Resources 51, 104122, 2013.

[73] Pendergast MT. M., Hoek E. M. V. "A review of water treatment membrane nanotechnologies", Energy and Environmental Science, 1-173, 2011.

[74] Shon H. K., Phuntsho S., Chaudhary D. S., Vigneswaran S., Cho J. "Nanofiltration for water and wastewater treatment - a mini review", Drink. Water Eng. Sci. 6, 47-53, 2013.

[75] Sharma V., Sharma A. "Nanotechnology: An Emerging Future Trend in Wastewater Treatment with its Innovative Products and Processes", International Journal of Enhanced Research in Science Technology \& Engineering 1, 1-8, 2012.

[76] Amin M. T., Alazba A. A., Manzoor U. "A review of Removal of Pollutants from Water/Wastewater Using Different Types of Nanomaterials", Advances in Materials Science and Engineering 2014, 825910, 1-24, 2014.

[77] Gehrke I., Geiser A., Somborn-Schulz A. "Innovations in nanotechnology for water treatment", Nanotechnol Sci Appl. 8, 1-17, 2015.

[78] http://www.epa.gov/oem/content/learning/response.htm

[79] Meridian Institute. "Overview and comparison of conventional water treatment technologies and nano based water treatment technologies", Global Dialogue on nanotechnology and the poor: opportunities and risks. Meridian Institute, Chennai, India, 2006.

[80] Şengül H., Theis, T., Ghosh, S. "Towards sustainable nanoproducts: An overview of nanomanufacturing methods', J Indust Ecol, 12, 329-359, 2008.

[81] Khanna V., Bakshi B. Lee L. "Carbon nanofiber production: Life cycle energy consumption and environmental impact", J Indust Ecol, 12, 394-410, 2008.

[82] Hund-Rinke K., Simon M. "Ecotoxic effect of photocatalytic active nanoparticles (TiO2) on algae and daphnids", Environ Sci Poll Res, 13, 225-232, 2006.

[83] Lovern B. Klaper R. "Daphnia magna mortality when exposed to titanium dioxide and fullerene (c60) nanoparticles", Environ Toxicol Chem, 25, 1132-1137, 2006.

[84] Templeton R., Ferguson P., Washburn K., Scrivens W. Chandler G. "Life-cycle effects of single-walled carbon nanotubes (SWNTs) on an estuarine meiobenthic copepod", Environmental Science and Technology, 40, 7387-7393, 2006.

[85] Federici G., Shaw B. Handy R. "Toxicity of titanium dioxide nanoparticles to rainbow trout (Oncorhynchusmykiss): Gill injury, oxidative stress, and other physiological effects", Aquatic Toxicol, 84, 415-430, 2007.

[86] Lovern S., Strickler J. Klaper R. "Behavioral and Physiological Changes in Daphnia magna when exposed to nanoparticle suspensions (Titanium Dioxide, Nano-C60, and C60HxC70Hx)", Environ Sci Technol 41, 4465-4470, 2007. 
[87] Scott-Fordsmand J., Krogh P., Schaefer M. Johansen A. "The toxicity testing of double-walled nanotubes contaminated food to Eisenia veneta earthworms", Ecotoxicol Environ Safety 71, 616-619, 2008.

[88] Takeda K, Suzuki K, Ishihara A, Kubo-Irie M, Fujimoto R, Tabata M, Oshio S, Nihei Y, Ihara T, Sugamata M. "Nanoparticles transferred from pregnant mice to their offspring can damage the genital and cranial nerve systems", J Health Sci 55, 95-102, 2009.

[89] Tsuchiya T, Oguri I, Yamakoshi Y Miyata N. "Novel harmful effects of [60] fullerene on mouse embryos in vitro and in vivo", FEBS Lett 393, 139-45, 1996.

[90] Lin S, Reppert J, Hu Q, Hudson J, Reid M, Ratnikova T, Rao A, Luo H, Ke P. "Uptake, Translocation, and Transmission of Carbon Nano materials in Rice Plants", Small 5:1128$1132,2009$.

[91] Monteiro-Rivere N.A., Nemanich R.J., Inman A.O., Wang Y.Y. Riviere J.E. "Multi-walled carbon nanotube interactions with human epidermal keratinocytes", Toxicology Letters, 155 377-384, 2005.

[92] Lam James J.T., McCluskey R. Hunter R.L. "Pulmonary Toxicity of Single-Wall Carbon Nanaotubes in Mice 7 and 90 days After Intratracheal Instillation', Toxicological Sciences, 77, 126-134, 2004.

[93] Donaldson K., Aitken R., Tran L., Stone V., Duffin R., Forrest G., Alexander A. "Carbon Nanotubes: A Review of Their Properties in Relation to Pulmonary Toxicology and Workplace Safety", Toxicology Sciences, 92 5-22, 2006.

[94] Shvedova A.A., Kish E.R., Mercer R., Murray A.R., Johnson V.J., Potapovich A.I., Tyurina Y.Y., Gorelik O., Arepalli S., Schweglar-Berry D., Hubbs A.F., Antonini J., Evans D.E., Ku B.K., Ramsey D., Maynard A., Kagan V.E., Castrnova V. Baron P. "Unusual inflammatory and fibrogenic pulmonary responses to single-wall carbon nanotubes in mice", Am J Physio Lung Cell Mol Physio. 289, L698-708. Epub, 2005.

[95] Worle-Knirsch J.M., Pulskamp K., Krug H.F. "'Oops They Did it Again! Carbon Nanotubes Hoax Scientists in Viability Assays", Nano Letters, 6, 1261-1268, 2006.

[96] Joey D. M., Pengfei C., Rigoberto C. A. "Smart Cements and cement Additives for oil and gas Operations", Journal of Petroleum Science and Engineering, http://dx.doi.org/10.1016/j.petrol. 02.009, 2015.

[97] Kong J., Franklin N.R., Zhou C., Chapline M.G., Peng S., Cho K., Dai H. "Nanotube molecular wires as chemical sensors', Science, 287,622-625, 2000. 